\title{
Transcutaneous pulsed radiofrequency treatment in chronic knee pain, usefull or useless?
}

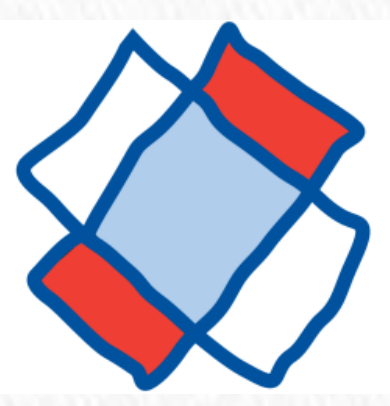

Y.B. Molero Díez¹, R. Sanchis Dux¹, F.A. Ruíz Simón¹, M.E. Michel Tactuk¹, Á. Sánchez Tabernero ${ }^{1}$, M. García Castañoํ․ ${ }^{1}$ Hospital Virgen de la Concha, Departamento de Anestesiología y Reanimación, Zamora, Spain.

\section{Background and Aims:}

Pulsed radiofrequency treatment is a minimally invasive procedure highly used in pain units. Several studies show that pulsed radiofrequency applied to chronic knee pain seems to be effective. A magnetic field is created between two shields, one active and other dispersive, on the pain zone. In this study, we investigated effectiveness of transcutaneous pulsed radiofrequency (PRF) applied in patients with chronic knee pain due to knee arthrosis.

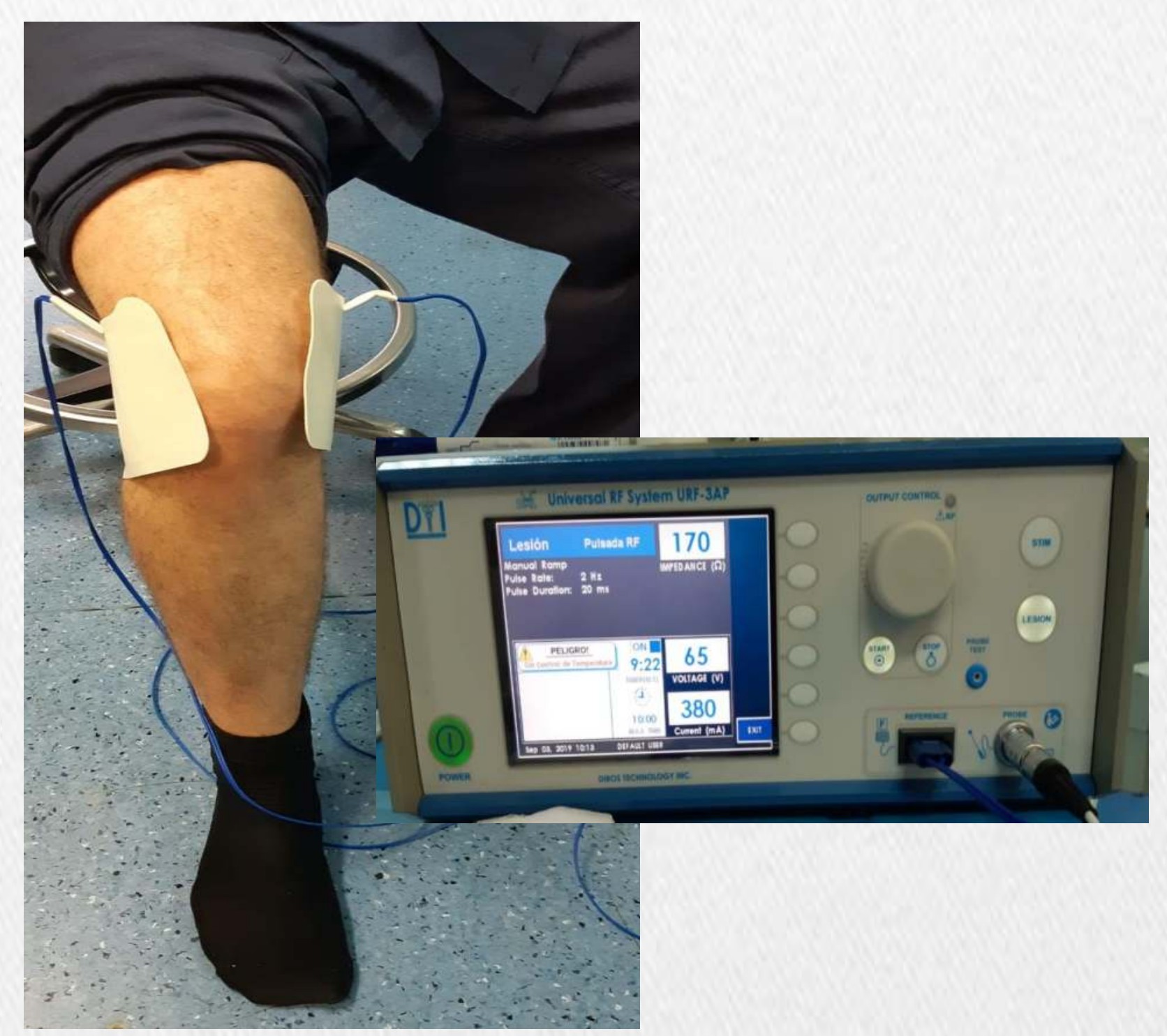

\section{Methods:}

Local committee authorizes observational anonymous retrospective study without Ethics Committee approval. We reviewed files of 44 patients who recieved knee transcutaneous PRF for chronic knee arthrosis between January 2014 and December 2018 at chronic pain unit in Zamora hospital, Spain. We evaluate by Visual Analogic Scale (VAS) the patient and phisician global impression about pain relief. Furthermore, gender was also collected for statistic evaluation. The technic was started as $60 \mathrm{~V}$ for 10 minutes.

- $72,7 \%$ of the patients were female.

- The mean initial VAS scores of the patients were 8 in activity and 4 in rest. One month after the treatment, it was found, respectively, to be 7 and 2, not being significant.

- 40,9\% presented "no changes" in pain.

- 50,1\% improved.

\section{Conclusions:}

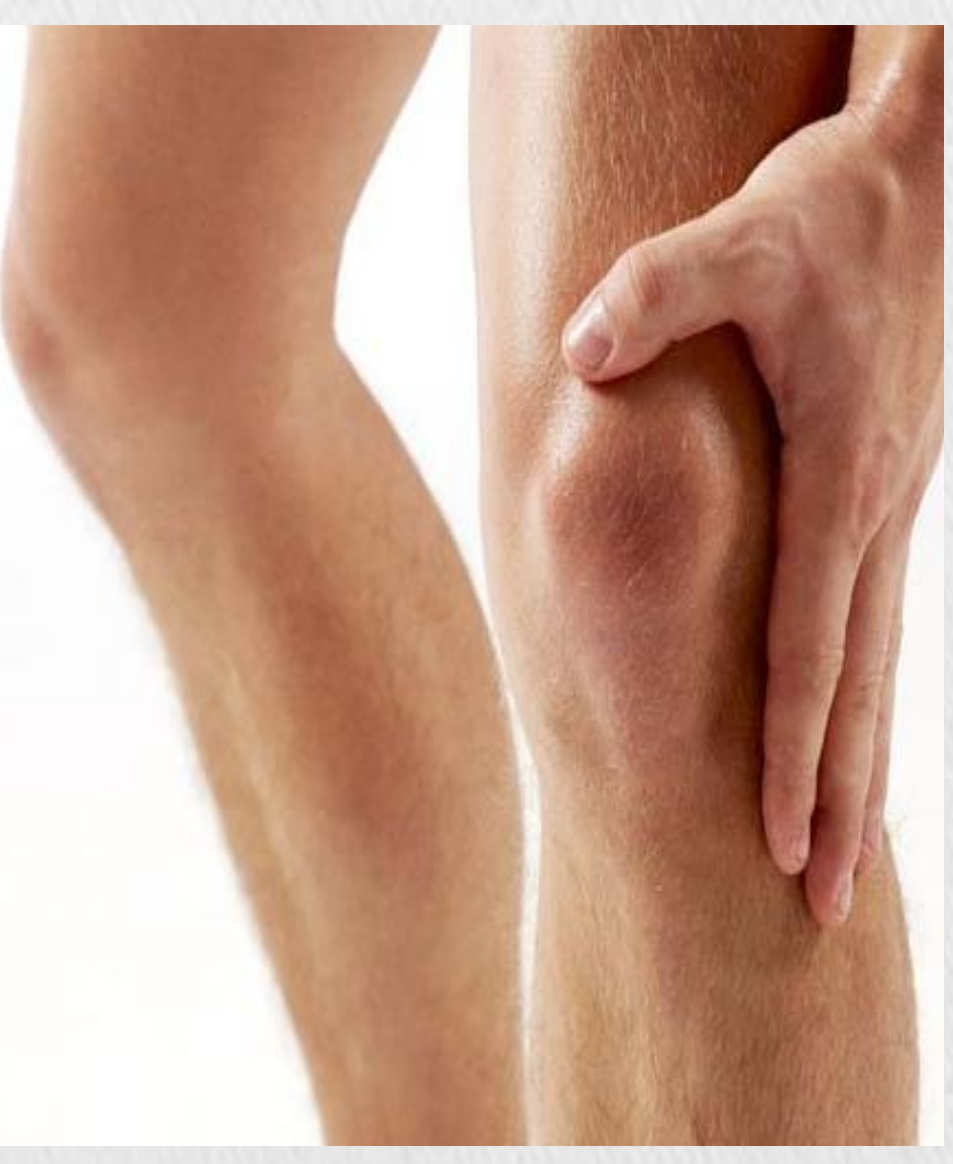

- Patients VAS showed a light improvement after the treatment.

- The majority refers to be like before the treatment.

- Differences between gender were not found. 